\title{
Modeling and Simulation of Surface Roughness in Wire Electrical Discharge Turning Process
}

\author{
Xiaoteng $\mathrm{Ma}{ }^{\text {a }}$, Yadong Gong ${ }^{\mathrm{b}}$ and Yao Sun ${ }^{\mathrm{c}}$ \\ School of Mechanical Engineering \& Automation, Northeastern University, Shenyang, China \\ amxt0823@163.com, bgongyd@mail.neu.edu.cn, csy547515291@163.com
}

Keywords: LS-WEDT; Model; Surface roughness; MATLAB; Surface topography.

\begin{abstract}
This research aims to investigate the effects of speed parameters, such as workpiece rotation speed and feed rate, on the surface roughness in LS-WEDT (low speed wire electrical discharge turning) process. Then a mathematical model of surface roughness can be built to deduce the formulas predicting the surface roughness values. In addition, with designing the experiments to verify the reliability of the model at a specified WEDT process conditions, it is demonstrated that the predicted $\mathrm{Ra}$ values are closer to the experimental $\mathrm{Ra}$ values at larger pitch (above $0.05 \mathrm{~mm}$ ). At smaller pitch (below $0.05 \mathrm{~mm}$ ), the other evolutional model is built to predict the surface topography, and then calculate the surface roughness with MATLAB software. It is found that the predicted surface topography has several geometric characteristics in accordance with the experimental surface topography and the predicted $\mathrm{Ra}$ values are closer to the experimental $\mathrm{Ra}$ values. Therefore, the surface roughness and topography can be quantitatively predicted from the specified WEDT parameters.
\end{abstract}

\section{Introduction}

Wire electrical discharge machining (WEDM) is a new nontraditional machining process based on electrical discharge machining $(\mathrm{EDM})^{[1-2]}$. The WEDM is a complex process that the workpiece material is removed in the form of high temperature melting without direct contact and macroscopic forces. Therefore, The WEDM is not restricted by the physical properties of materials and is widely applied to deal with the complex micro parts and micro mold of the difficult-to-machine materials such as hard metal, etc.

Wire electrical discharge turning (WEDT) is a significant configuration of WEDM process, which employs an additional rotary axis to conventional five-axis WEDM machine in order to produce sixaxis WEDT forms ${ }^{[3-4]}$. The concept of six-axis WEDT is illustrated in Fig. 1. The Brass wire slides to remove the work-material in the controlled of $\mathrm{X}$ and $\mathrm{Y}$ axis.

WEDT is a transient stochastic process. There are many factors affecting the surface integrity in WEDT process such as the electric parameters, speed parameters, electrode polarity, tool electrode materials, dielectric properties, etc. Researchers have attempted to study the effect of process

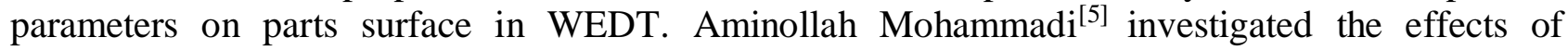
machining parameters on material removal rate and expressing the mathematical relationship between machining parameters and material removal rate in WEDT. Jun $\mathrm{Qu}^{[6]}$ investigated the surface integrity and roundness of cylindrical wire EDM carbide and brass parts, and derived the model of the closedform solution of the arithmetic average surface roughness of the simulated surface generated by the cylindrical wire EDM process. ZHOU Tianfeng ${ }^{[7]}$ investigated the thermal effects at various EDM conditions, and build the model of surface topography evolution. 


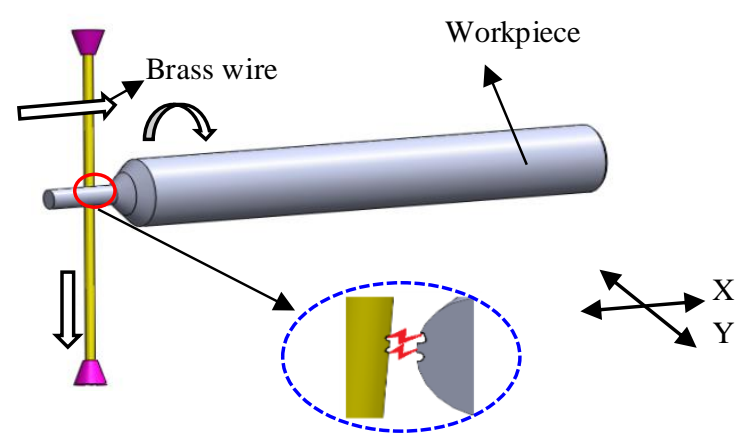

Fig. 1 The concept of six-axis WEDT

This research aims to investigate the relationship between the speed parameters and the surface roughness in WEDT. Then a mathematical model of WEDT process is built to predict the surface roughness on ideal conditions ${ }^{[6]}$. Furthermore, the other evolutional model is built to predict the surface topography, and then calculate the surface roughness with MATLAB software. Finally, the laws that speed parameters affect the surface roughness will be inferred to improve the accuracy and the precision of WEDT process.

\section{Surface roughness modeling}

Wire electrical discharge machining (WEDM) is a thermo-electrical process in which material is eroded from the workpiece by a series of discrete sparks. The surface topography and integrity of machined workpiece are related with the size and the shape of a single pulse discharge crater. The simulated surface roughness model can be established in WEDT process according to the relative geometric movement model of wire electrode and workpiece electrode, as shown in Fig.2.

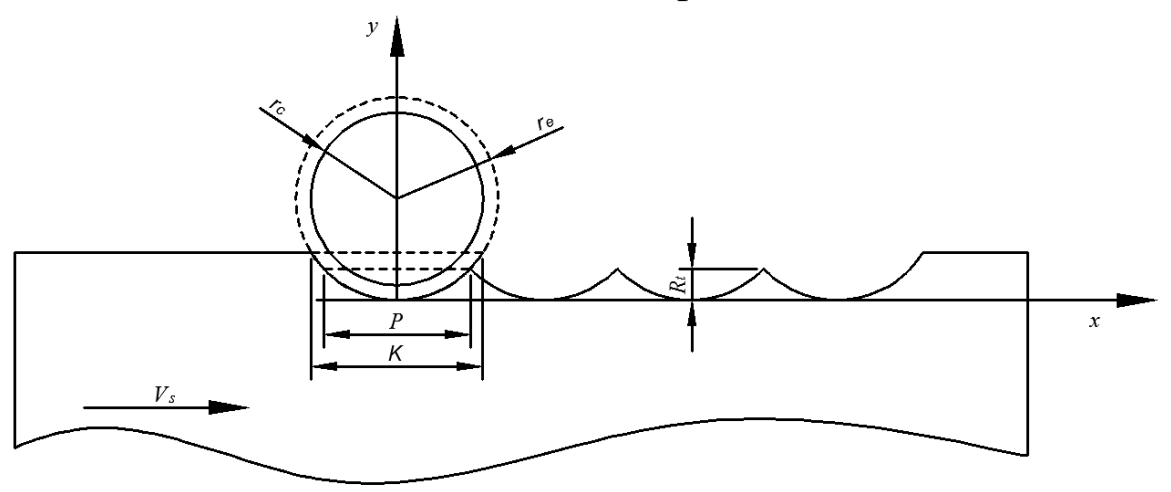

Fig.2 Cross-section of machined workpiece in WEDT

The workpiece material is eroded by a series of discharge sparks to form the helical-groove in the surface contour. The width of helical-groove, $K$, is related to the radius of wire, $r_{\mathrm{c}}$, and the gap between wire and workpiece, $\Delta d$. The pitch of helical-groove, $P$, can be calculated as shown in Eq. (1) where the $V_{s}$ is workpiece feed rate, and the $V_{n}$ is workpiece rotation speed.The radius of cross-section arc, $r_{e}$, can be approximately considered as the sum of $r_{c}$ and $\Delta d$.

$$
P=\frac{V_{s}}{V_{n}}
$$

With defining the XY coordinate system as shown in Fig.2, the locus equation of ideal arc can be deduced as:

$$
x^{2}+\left(y-r_{e}\right)^{2}=r_{e}^{2} \quad\left(-\frac{P}{2} \leq x \leq \frac{P}{2}\right)
$$

According to the geometrical relationship in Fig.1, the peak to valley surface roughness, $R_{t}$, of the ideal machined surface can be deduced as:

$$
R_{t}=r_{e}-\sqrt{r_{e}^{2}-(P / 2)^{2}}
$$

However, the arithmetic average roughness, $R_{a}$, is usually used to assess the surface integrity, which can be deduced as: 


$$
R_{a}=\frac{1}{p} \int_{-p / 2}^{p / 2}|y-\bar{y}| d x
$$

Where $\bar{y}$ is the center line of the machined surface profile, which can be deduced as:

$$
\bar{y}=\frac{1}{p} \int_{-p / 2}^{p / 2} y d x
$$

where $-\frac{p}{2} \leq x \leq \frac{p}{2}$, define a positive parameter on $\mathrm{X}$-axis, $\mathrm{xa}$, which meets the condition that $x_{a}^{2}+\left(\bar{y}-r_{e}\right)^{2}=r_{e}^{2}$. Thus:

$$
x_{a}=\sqrt{2 r_{e} \bar{y}-\bar{y}^{2}}
$$

Therefore, the arithmetic average roughness, Ra , Fig. 2 can be deduced as:

$$
R_{a}=\frac{2}{p} \int_{0}^{p / 2}|y-\bar{y}| d x=\frac{2}{p}\left[\int_{0}^{x_{a}}(\bar{y}-y) d x+\int_{x_{a}}^{p / 2}(y-\bar{y}) d x\right]
$$

\section{Experimental evaluation}

According to the results of simulation, select the workpiece rotation speed, $V_{n}$, and workpiece feed rate, $V_{s}$, as speed parameters to design two sets of verified experiments, Experiment 1 and Experiment 2, as shown in Table 1 and Table 2. In the experiments, the material of workpiece is TC4 which has a diameter of $3 \mathrm{~mm}$. The material of wire electrode is brass which has a diameter of $0.2 \mathrm{~mm}$. The peak current is $5 \mathrm{~A}$, the open circuit voltage is $50 \mathrm{~V}$, and the pulse-on time is $6 \mu \mathrm{s}$. The width of helical-groove can be measured in the experiment, which is $0.2 \mathrm{~mm}$. The electric discharge gap can be considered as $0.01 \mathrm{~mm}$ according to massive investigation. $R_{\mathrm{a}}$ can be measured by $3 \mathrm{D}$ surface profilometer which is the weighted average result that select three measured fields which each of is measured three times.

Table 1 The experimental design and results for Experiment 1

\begin{tabular}{cccccc}
\hline Serial number & $V_{\mathrm{n}} /\left(\mathrm{r} \cdot \mathrm{min}^{-1}\right)$ & $V_{\mathrm{s}} /\left(\mathrm{mm} \cdot \mathrm{s}^{-1}\right)$ & $P / \mathrm{mm}$ & $R_{\mathrm{a}}($ measured $) / \mu \mathrm{m}$ & $R_{\mathrm{a}}($ simulated $) / \mu \mathrm{m}$ \\
\hline 1 & 10 & 1 & 0.1 & 3.24 & 3.05 \\
2 & 15 & 1 & 0.067 & 1.31 & 1.32 \\
3 & 20 & 1 & 0.05 & 0.81 & 0.76 \\
4 & 25 & 1 & 0.04 & 0.80 & 0.47 \\
5 & 30 & 1 & 0.033 & 0.86 & 0.33 \\
6 & 35 & 1 & 0.029 & 0.89 & 0.24 \\
7 & 40 & 1 & 0.025 & 0.84 & 0.18 \\
\hline
\end{tabular}

Table 2 The experimental design and results for Experiment 2

\begin{tabular}{cccccc}
\hline Serial number & $V_{\mathrm{n}} /\left(\mathrm{r} \cdot \mathrm{min}^{-1}\right)$ & $V_{\mathrm{s}} /\left(\mathrm{mm} \cdot \mathrm{s}^{-1}\right)$ & $P / \mathrm{mm}$ & $R_{\mathrm{a}}($ measured $) / \mu \mathrm{m}$ & $R_{\mathrm{a}}$ (simulated $) / \mu \mathrm{m}$ \\
\hline 1 & 25 & 0.1 & 0.004 & 0.87 & 0.0047 \\
2 & 25 & 0.5 & 0.02 & 0.85 & 0.117 \\
3 & 25 & 0.8 & 0.032 & 0.88 & 0.300 \\
4 & 25 & 1.0 & 0.04 & 0.80 & 0.47 \\
5 & 25 & 1.4 & 0.056 & 0.94 & 0.93 \\
6 & 25 & 1.6 & 0.064 & 1.18 & 1.22 \\
7 & 25 & 2.0 & 0.08 & 1.88 & 1.92 \\
\hline
\end{tabular}

In Experiment 1, seven workpiece rotation speeds were tested for the WEDT process of TC4 on the basis that workpiece feed rate was $1 \mathrm{~mm} / \mathrm{min}$. The surface roughness of the five workpieces machined in Experiment 1 is shown in Fig.3(a). In Experiment 2, seven workpiece feed rates were tested for the WEDT process of TC4 on the basis that workpiece feed rate was $25 \mathrm{r} / \mathrm{min}$. The surface roughness of the five workpieces machined in Experiment 2 is shown in Fig.3(b). 


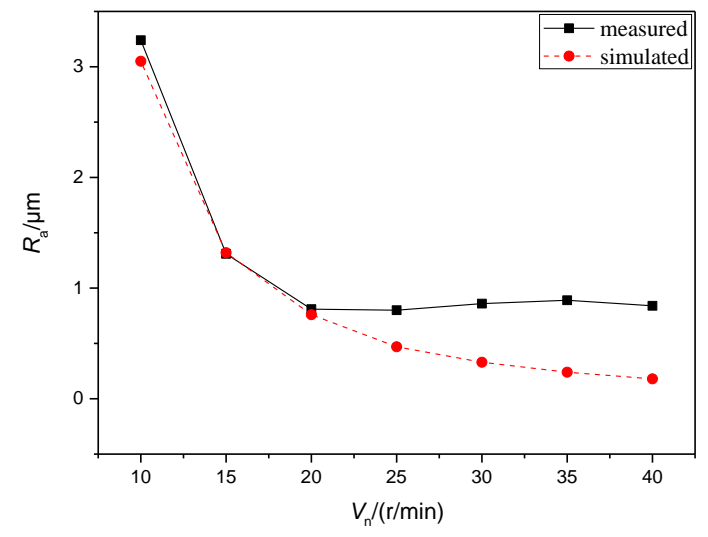

(a) Experiment 1

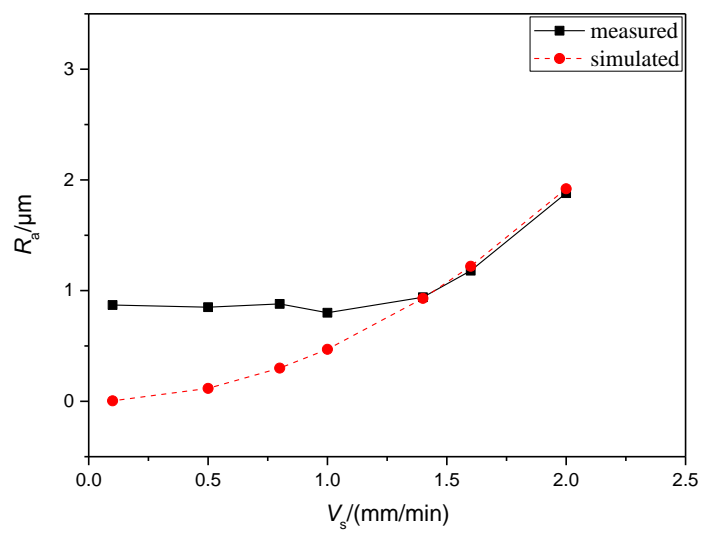

(b) Experiment 2

Fig.3 The surface roughness of the WEDT workpieces machined in experiments

As shown in Table 1 and Table 2, higher workpiece rotation speed and lower workpiece feed rate will generate smaller pitch of helical-groove.

From the Fig.3(a), it can be seen that increasing workpiece rotation speed will cause to decrease surface roughness for an ideal surface, and the measured surface roughness values are approximately identical with ideal surface roughness values when the workpiece rotation speed is lower than 20 $\mathrm{r} / \mathrm{min}$. Three sets of surface topography of machined workpieces are measured by $3 \mathrm{D}$ surface profilometer when the workpiece rotation speed is $10 \mathrm{r} / \mathrm{min}, 20 \mathrm{r} / \mathrm{min}$ and 30r/min, as shown in Fig.4.

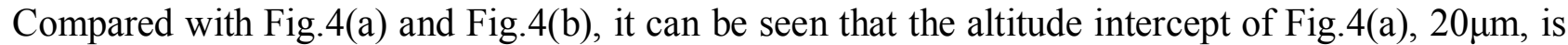
larger than the altitude intercept of Fig.4(b), $5 \mu \mathrm{m}$. However, For Fig.4(c), the measured surface roughness value of is larger than the simulated surface roughness value due to the additional craters on the WEDT machined surface.

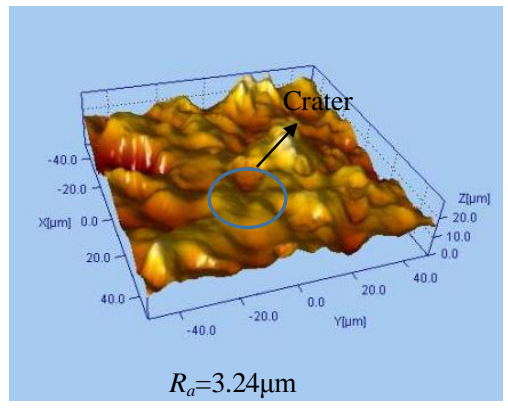

(a) $V_{n}=10 \mathrm{r} / \mathrm{min}$

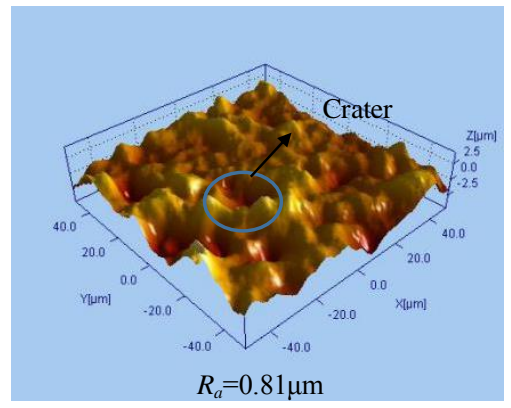

(b) $V_{n}=20 \mathrm{r} / \mathrm{min}$

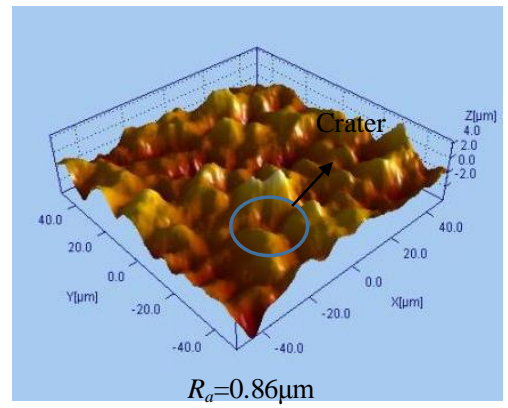

(c) $V_{n}=30 \mathrm{r} / \mathrm{min}$

Fig.4 The 3D surface topography of machined workpiece

From the Fig.3(b), it can be seen that increasing workpiece feed rate will cause to increase surface roughness for an ideal surface, and the measured surface roughness are approximately identical with ideal surface roughness when the workpiece feed rate is higher than $1.4 \mathrm{~mm} / \mathrm{min}$. However, due to the additional craters on the WEDT machined surface, the measured surface roughness values are slightly higher than the ideal surface roughness when the workpiece feed rate is lower than $1.4 \mathrm{~mm} / \mathrm{min}$.

\section{Modeling evolution}

According to the Experiment1 and Experiment 2, it can be seen that with the pitch of helicalgroove smaller, until below $0.05 \mathrm{~mm}$, the surface roughness value of simulation will further deviate from the the surface roughness value of experiment, and the measured surface roughness will tend to be steady state fluctuations, because the pitch of helical-groove is so small that the size of crater can not be no longer ignored. Therefore, the workpiece surface can be considered as being covered with countless stochastic discharge craters. 
The cross-section of single pulse discharge crater in WEDT process can be considered as spherical crown model, as shown in Fig.5. $D$ and $H$, respectively, represents the diameter and depth of the single discharge crater.

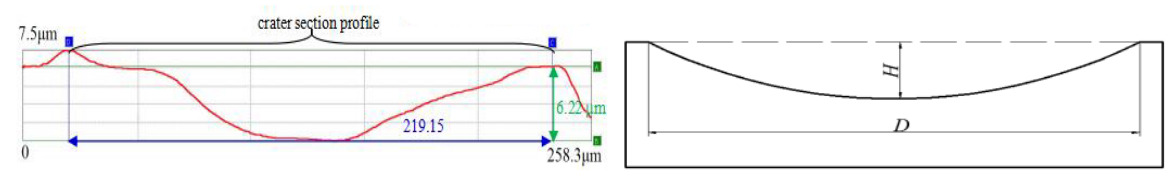

Fig.5 The experimental profile and geometric model of single pulse discharge crater

The surface topography is covered with countless stochastic discharge craters, which can be simulated by MATLAB software. According to the definition of the arithmetic average roughness, as shown in Eq.(8), regard the $\mathrm{x}$-axis value of surface topography simulated by MATLAB software as the roughness height value, and then calculate the arithmetic average roughness. helical-groove is $0.025 \mathrm{~mm}$ is studied by simulating with MATLAB software, as shown in Fig.6. The experimental suraface topography is measured by super depth of field microscope. It can be seen that the surface topography prediction of simulation has several geometric characteristics in accordance with the surface topography of experiments, and the surface roughness value of simulation, $0.91 \mu \mathrm{m}$, is closer to the surface roughness value of experiment, $0.84 \mu \mathrm{m}$, than the surface roughness value of ideal model, $0.07 \mu \mathrm{m}$.

$$
R_{a}=\frac{1}{L} \sum f(x) d x
$$
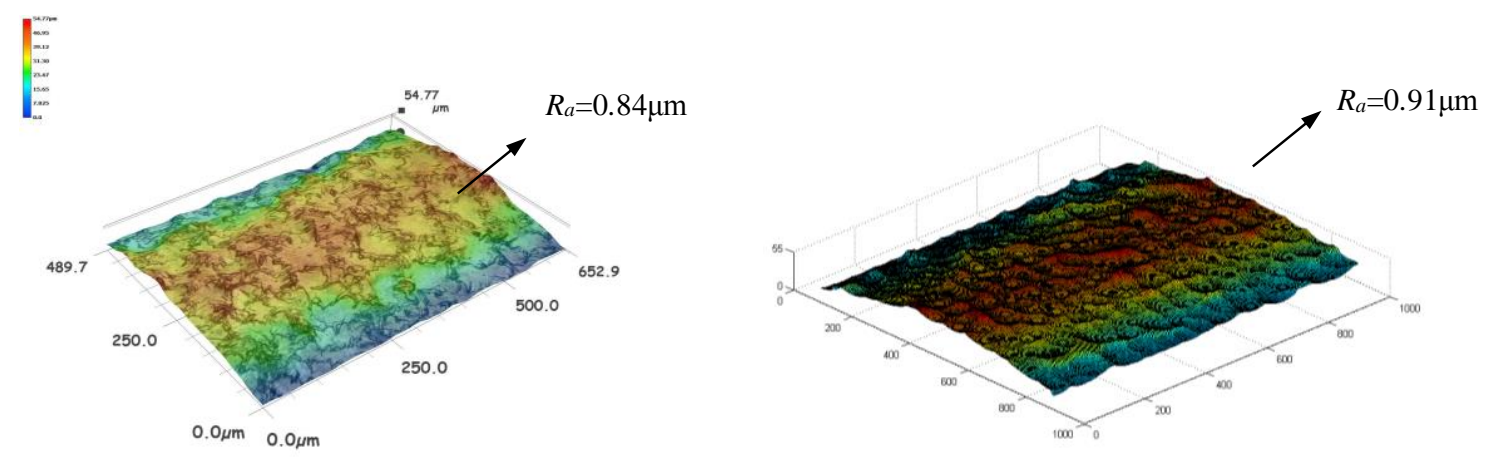

Fig. 6 The surface topography of experiment (left) and simulation (right)

\section{Conclusions}

This research focuses on modeling the surface topography for predicting the surface roughness in WEDT process, the following specific conclusions can be drawn:

A new mathematical model is proposed to predict the surface roughness. It is shown that the predicted $R_{a}$ values are closer to the experimental $R_{a}$ values at larger pitch (above $0.05 \mathrm{~mm}$ ). At lower pitch (below $0.05 \mathrm{~mm}$ ), the predicted $R_{a}$ values are lower due to the pitch is so small that the size of crater can not be ignored.

At lower pitch (below $0.05 \mathrm{~mm}$ ), the other evolutional model with considering the crater size is built to predict the surface topography, and then calculate the surface roughness with MATLAB software. It is found that the predicted $R_{a}$ values are closer to the experimental $R_{a}$ values.

\section{References}

[1] Gong Y D, Sun Y and Wen X L. Experimental study on surface integrity of Ti-6Al-4V machined by LS-WEDM. Int J Adv Manuf Technol, 2017, 88, p.197-207.

[2] Gong Y D, Sun Y and Wen X L. Experimental study on accuracy and surface quality of TC2 in LS-WEDM multiple cuts. Journal of the Brazilian Society of Mechanical Sciences and Engineering,2016, 38, p.2421-2433. 
[3] Samuel G L. Analysis on the effect of discharge energy on machining characteristics of wire electrical discharge turning. Journal of Engineering Manufacture, 2016, Vol.230(11), p.064-2081.

[4] Janardhan V and Samuel GL. Pulse train data analysis to investigate the effect of machining parameters on the performance of Wire Electro Discharge Turning (WEDT) process. Int J Mach Tool Manu 2010, 50(9), p.775-788.

[5] Aminollah M, Alireza F T and Ehsan E. Statistical analysis of wire electrical discharge turning on material removal rate. Journal of Materials Processing Technology, 2008, 205: 283-289.

[6] Jun Qu, Albert J.Shih and Ronald O.Scattergood. Development of the Cylindrical Wire Electrical Discharge Machining Process, Part 2: ASME J. Manuf. Sci. Eng. 2002, 124, p.708-714.

[7] ZHOU Tianfeng, MA Lizheng and LIANG Zhiqiang.Modeling and Simulation of Surface Topography Evolution in Electrical Discharge Machining (EDM). Advanced Materials Research, 2014, 1017, p.764-769. 